\title{
Analisis dinamik model predator-prey tipe Gause dengan wabah penyakit pada prey
}

Rusdianto Ibrahim, Lailany Yahya, Emli Rahmi, and Resmawan

To cite this article:

R. Ibrahim, L. Yahya, E. Rahmi, and R. Resmawan, "Analisis dinamik model predator-prey tipe Gause dengan wabah penyakit pada prey", Jambura J. Biomath, vol. 2, no. 1, pp. 20-28, 2021

DOI: $h$ ttps://doi.org/10.34312/jjbm.v2i1.10363

(C) 2021 Author(s).

\section{Articles You may be interested in}

Bifurkasi Hopf pada model prey-predator-super predator dengan fungsi respon yang berbeda

D. Savitri and H. S. Panigoro

http://dx.doi.org/10.34312/jjbm.v1i2.8399

Analisis kestabilan model predator-prey dengan infeksi penyakit pada prey dan pemanenan proporsional pada predator

S. Maisaroh, Resmawan, and E. Rahmi

http://dx.doi.org/10.34312/jjbm.v1i1.5948

Bifurkasi Hopf pada model Lotka-Volterra orde-fraksional dengan Efek Allee aditif pada predator

H. S. Panigoro and D. Savitri

http://dx.doi.org/10.34312/jjbm.v1i1.6908

Discrete-time prey-predator model with $\theta$-logistic growth for prey incorporating square root functional response

P. K. Santra

http://dx.doi.org/10.34312/jjbm.v1i2.7660

A stage-structure Rosenzweig-MacArthur model with effect of prey refuge

L. K. Beay and M. Saija

http://dx.doi.org/10.34312/jjbm.v1i1.6891 


\title{
Analisis dinamik model predator-prey tipe Gause dengan wabah penyakit pada prey
}

\author{
Rusdianto Ibrahim ${ }^{1}$, Lailany Yahya ${ }^{2}$, Emli Rahmi ${ }^{3,}{ }^{*}, \operatorname{Resmawan}^{4}$ \\ 1,2,3,4 Jurusan Matematika, Universitas Negeri Gorontalo, Bone Bolango 96119, Indonesia \\ *Corresponding author: emlirahmi@ung.ac.id
}

\begin{abstract}
Abstrak
Artikel ini mempelajari dinamika dari model predator-prey tipe Gause dengan adanya wabah penyakit pada populasi prey. Model yang dibangun merupakan model deterministik yang mengasumsikan prey terbagi atas dua kompartemen, yaitu prey rentan dan prey terinfeksi, dan keduanya dimangsa oleh predator secara bilinear. Hasil analisis menunjukkan bahwa terdapat lima titik kesetimbangan secara biologis, yaitu titik kepunahan semua populasi, titik kepunahan prey terinfeksi dan predator, titik kepunahan prey terinfeksi, titik kepunahan predator, dan titik eksistensi seluruh populasi. Titik kepunahan semua populasi selalu tidak stabil sedangkan keempat lainnya stabil asimtotik lokal secara kondisional. Simulasi numerik berupa potret fase diberikan untuk menunjukkan kestabilan di setiap titik kesetimbangan yang bersesuaian dengan hasil-hasil analisis sebelumnya.
\end{abstract}

Kata Kunci: Predator-prey; Penyebaran Penyakit; Kestabilan Lokal

\begin{abstract}
This article studies the dynamics of a Gause-type predator-prey model with infectious disease in prey. The constructed model is a deterministic model which is assumes the prey is divided into two compartments i.e. susceptible prey and infected prey, and both of them are hunted by predator bilinearly. It is investigated that the there exist five biological equilibrium points such as all population extinction point, infected prey and predator extinction point, infected prey extinction point, predator extinction point, and co-existence point. We find that all population extinction point always unstable while others are conditionally locally asymptotically stable. Numerical simulations as well as the phase portraits are given to support the analytical results.
\end{abstract}

Keywords: Predator-prey; Infectious Disease; Local Stability

\section{Pendahuluan}

Interaksi antara dua atau lebih spesies dalam suatu ekosistem merupakan topik yang populer dalam pemodelan matematika karena menyangkut eksistensi dari populasi spesies-spesies tersebut. Salah satu model interaksi antara dua spesies yang memiliki perkembangan pesat dalam pemodelan matematika yaitu model predator-prey, sebagai contoh lihat [1-8]. Selain karena adanya interaksi antara populasi, eksistensi dari suatu populasi juga dipengaruhi oleh adanya infeksi penyakit baik yang mewabah secara tertutup dalam suatu populasi ataupun menyebar lintas populasi. Wabah ini dapat diakibatkan oleh virus, bakteri, dan parasit [9-14]. Dalam artikel ini, dipelajari interaksi antara predator dan prey dengan wabah penyakit pada prey. Diberikan beberapa asumsi berikut untuk membangun model yaitu:

1. Hubungan antara dua populasi mengikuti interaksi predator-prey tipe Gause [15] dengan $x$ dan $y$ masingmasing menyatakan populasi prey dan predator.

2. Prey terbagi menjadi dua sub populasi, yaitu prey rentan $x_{S}$ dan prey terinfeksi $x_{I}$. Prey rentan tumbuh secara logistik dengan laju pertumbuhan intrinsik $r$ dan daya dukung lingkungan K. Prey terinfeksi tidak memberikan kontribusi terhadap laju kelahiran prey rentan, namun turut bersaing mendapatkan makanan dengan prey rentan. Laju infeksi prey rentan menjadi prey terinfeksi diasumsikan bilinear yang disimbolkan dengan $\beta$. Selain itu, karena adanya penyakit, prey terinfeksi mati dengan laju kematian $\alpha$.

3. Kedua sub populasi prey dimangsa oleh predator mengikuti fungsi respon predator Holling tipe-I dengan laju pemangsaan prey rentan $m_{1}$ dan laju pemangsaan prey terinfeksi $m_{2}$. Kedua pemangsaan yang dilakukan memberikan kontribusi terhadap laju kelahiran predator dengan $b_{1}$ adalah laju konversi pemangsaan prey rentan menjadi laju kelahiran predator dan $b_{2}$ adalah laju konversi pemangsaan prey terinfeksi menjadi laju kelahiran predator. Predator mati secara alami dengan laju kematian $\delta$. 
Dengan asumsi tersebut, dibangun model sebagai berikut.

$$
\begin{aligned}
\frac{d x_{S}}{d t} & =r x_{S}\left(1-\frac{x_{S}+x_{I}}{K}\right)-m_{1} x_{S} y-\beta x_{S} x_{I} \\
\frac{d x_{I}}{d t} & =\beta x_{S} x_{I}-m_{2} x_{I} y-\alpha x_{I} \\
\frac{d y}{d t} & =b_{1} x_{S} y+b_{2} x_{I} y-\delta y
\end{aligned}
$$

dengan $x_{S}(0) \geq 0, x_{I}(0) \geq 0, y(0) \geq 0$ dan $r, K, m_{1}, m_{2}, b_{1}, b_{2}, \beta, \alpha, \delta>0$. Beberapa model yang relevan dengan (1) dapat dilihat pada [16-22]. Penelitian yang paling mendekati model (1) dikerjakan oleh Hasan dkk. [17] dan Maisaroh dkk. [18] yang masing-masing mengasumsikan adanya pemanenan konstan dan proposional pada predator, sedangkan pada artikel ini diasumsikan tidak ada pemanenan pada kedua populasi. Penelitian yang serupa juga dipelajari oleh Panigoro dkk. [16] yang secara asumsi sama, namun menggunakan operator yang berbeda yaitu operator turunan fraksional Caputo. Panigoro dkk [16] juga melakukan penskalaan terhadap model untuk mempermudah analisis dinamik yang dilakukan. Dalam artikel ini digunakan persamaan diferensial orde-satu dan tidak dilakukan nondimensionalisasi sehingga makna biologis dari model dapat dipertahankan.

Artikel ini disusun sebagai berikut. Pada Pokok Bahasan 2 diberikan pembuktian bahwa model layak secara biologis yaitu memiliki solusi tak negatif dan selalu terbatas. Pada Pokok Bahasan 3 diidentifikasi eksistensi titik kesetimbangan biologis dari model (1) dan dipelajari kestabilan lokal dari titik kesetimbangan tersebut. Untuk memperlihatkan dinamika secara lokal di sekitar titik kesetimbangan, diberikan simulasi numerik berupa potret fase pada Pokok Bahasan 4. Artikel ini diakhiri dengan memberikan kesimpulan pada Pokok Bahasan 5.

\section{Keberartian Model Matematika Biologi}

Model (1) dikatakan layak secara biologis jika memenuhi beberapa kriteria berikut:

1. Untuk suatu kondisi awal kepadatan populasi tertentu yang tak-negatif, kepadatan populasi akan selalu tak-negatif sepanjang $t \rightarrow \infty$.

2. Kepadatan populasi harus selalu terbatas sepanjang $t \rightarrow \infty$ mengingat bahwa daya dukung lingkungan seperti sumber daya dan kondisi tempat tinggal atau habitat yang ada juga memiliki keterbatasan.

Dengan demikian diberikan teorema berikut.

Teorema 1. Untuk setiap nilai awal $\left(x_{S}(0), x_{I}(0), y(0)\right)$ tak negatif, solusi $x_{S}(t), x_{I}(t)$, dan $y(t)$ selalu tak-negatif dan terbatas sepanjang $t \rightarrow \infty$.

bukti. Pertama-tama, akan ditunjukkan bahwa solusi selalu tak negatif. Perhatikan bahwa model (1) dapat dituliskan menjadi

$$
\frac{d x_{S}}{d t}=F_{1}\left(x_{S}, x_{I}, y\right) x_{S}, \frac{d x_{I}}{d t}=F_{2}\left(x_{S}, x_{I}, y\right) x_{I}, \frac{d y}{d t}=F_{3}\left(x_{S}, x_{I}, y\right) y,
$$

dengan

$$
\begin{aligned}
& F_{1}\left(x_{S}, x_{I}, y\right)=r\left(1-\frac{x_{S}+x_{I}}{K}\right)-m_{1} y-\beta x_{I}, \\
& F_{2}\left(x_{S}, x_{I}, y\right)=\beta x_{S}-m_{2} y-\alpha, \\
& F_{3}\left(x_{S}, x_{I}, y\right)=b_{1} x_{S}+b_{2} x_{I}-\delta .
\end{aligned}
$$

Dari pers. (2) diperoleh

$$
\frac{d x_{S}}{x_{S}}=F_{1}\left(x_{S}, x_{I}, y\right) d t, \frac{d x_{I}}{x_{I}}=F_{2}\left(x_{S}, x_{I}, y\right) d t, \frac{d y}{y}=F_{3}\left(x_{S}, x_{I}, y\right) d t
$$

Dengan menyelesaikan pers. (3) didapatkan

$$
x_{S}=x_{S}(0) \exp \left\{\int_{0}^{t} F_{1}\left(x_{S}, x_{I}, y\right) d t\right\}, x_{I}=x_{I}(0) \exp \left\{\int_{0}^{t} F_{2}\left(x_{S}, x_{I}, y\right) d t\right\}, y=y(0) \exp \left\{\int_{0}^{t} F_{3}\left(x_{S}, x_{I}, y\right) d t\right\} \text {. }
$$


Karena $\exp \left\{\int F_{i}\left(x_{S}, x_{I}, y\right) d t\right\}>0, \forall i=1 . .3, x_{S}(0) \geq 0, x_{I}(0) \geq 0$, dan $y(0) \geq 0$ maka terbukti bahwa $x_{S}(t)$, $x_{I}(t)$, dan $y(t)$ selalu tak-negatif $t \rightarrow \infty$.

Selanjutnya akan ditunjukkan bahwa $x_{S}(t), x_{I}(t)$, dan $y(t)$ terbatas sepanjang $t \rightarrow \infty$. Diberikan fungsi definit positif sebagai berikut.

$$
\mathcal{V}\left(x_{S}(t), x_{I}(t), y(t)\right)=x_{S}+\left(\frac{r+\beta K}{\beta K}\right) x_{I}+\eta y .
$$

Jelas bahwa jika $V$ terbatas maka $x_{S}, x_{I}$, dan $y$ terbatas. Selanjutnya, berdasarkan pers. (4) didapatkan

$$
\begin{aligned}
\frac{d \mathcal{V}}{d t}+\zeta \mathcal{V}= & \frac{d x_{S}}{d t}+\left(\frac{r+\beta K}{\beta K}\right) \frac{d x_{I}}{d t}+\eta \frac{d y}{d t}+\zeta\left(x_{S}+\left(\frac{r+\beta K}{\beta K}\right) x_{I}+\eta y\right) \\
= & \left(r x_{S}\left(1-\frac{x_{S}+x_{I}}{K}\right)-m_{1} x_{S} y-\beta x_{S} x_{I}\right)+\left(\frac{r+\beta K}{\beta K}\right)\left(\beta x_{S} x_{I}-m_{2} x_{I} y-\alpha x_{I}\right) \\
& +\eta\left(b_{1} x_{S} y+b_{2} x_{I} y-\delta y\right)+\left(\zeta x_{S}+\zeta\left(\frac{r+\beta K}{\beta K}\right) x_{I}+\zeta \eta y\right) \\
= & r x_{S}-\frac{r}{K} x_{S}^{2}-\left(\frac{r}{K}+\beta\right) x_{S} x_{I}-m_{1} x_{S} y+\frac{\beta(r+\beta K)}{\beta K} x_{S} x_{I}-\frac{m_{2}(r+\beta K)}{\beta K} x_{I} y-\frac{\alpha(r+\beta K)}{\beta K} x_{I} \\
& +\eta b_{1} x_{S} y+\eta b_{2} x_{I} y-\eta \delta y+\zeta x_{S}+\frac{\zeta(r+\beta K)}{\beta K} x_{I}+\zeta \eta y \\
= & (r+\zeta) x_{S}-\frac{r}{K} x_{S}^{2}-\left(m_{1}-\eta b_{1}\right) x_{S} y-\left(\frac{m_{2}(r+\beta K)}{\beta K}-\eta b_{2}\right) x_{I} y \\
& -\frac{(r+\beta K)}{\beta K}(\alpha-\zeta) x_{I}-\eta(\delta-\zeta) y .
\end{aligned}
$$

Pilih $\eta<\min \left\{\frac{m_{1}}{b_{1}}, \frac{m_{2}(r+\beta K)}{b_{2} \beta K}\right\}$ dan $\zeta<\min \{\alpha, \delta\}$ sehingga

$$
\begin{aligned}
\frac{d \mathcal{V}}{d t}+\zeta \mathcal{V} & \leq(r+\zeta) x_{S}-\frac{r x_{S}^{2}}{K} \\
& =-\frac{r}{K}\left(x_{S}^{2}-\frac{(r+\zeta) K}{r} x_{S}+\frac{(r+\zeta)^{2} K^{2}}{4 r^{2}}\right)+\frac{(r+\zeta)^{2} K}{4 r} \\
& =-\frac{r}{K}\left(x_{S}-\frac{(r+\zeta) K}{2 r}\right)^{2}+\frac{(r+\zeta)^{2} K}{4 r} \\
& \leq \frac{(r+\zeta)^{2} K}{4 r}
\end{aligned}
$$

Dengan memanfaatkan teorema perbandingan [23] diperoleh

$$
0 \leq \mathcal{V}\left(x_{S}(t), x_{I}(t), y(t)\right) \leq \frac{(r+\zeta)^{2} K}{4 \zeta r}+\frac{\mathcal{V}\left(x_{S}(0), x_{I}(0), y(0)\right)}{e^{\zeta t}}
$$

Ketika $t \rightarrow \infty$ maka $0 \leq \mathcal{V}\left(x_{S}(t), x_{I}(t), y(t)\right) \leq \frac{(r+\zeta)^{2} K}{4 \zeta r}$. Dengan demikian, model (1) terbatas.

\section{Titik Kesetimbangan, Eksistensi, dan Kestabilannya}

Titik kesetimbangan model (1) diperoleh dengan menyelesaikan sistem persamaan berikut.

$$
\begin{array}{r}
{\left[r\left(1-\frac{x_{S}+x_{I}}{K}\right)-m_{1} y-\beta x_{I}\right] x_{S}=0} \\
{\left[\beta x_{S}-m_{2} y-\alpha\right] x_{I}=0} \\
{\left[b_{1} x_{S}+b_{2} x_{I}-\delta\right] y=0}
\end{array}
$$

Dengan demikian, diperoleh lima titik kesetimbangan sebagai berikut.

1. $E_{0}:=(0,0,0)$ dimana titik kesetimbangan pertama ini menunjukan suatu kondisi ketika terjadi kepunahan pada semua populasi. 
2. $E_{1}:=(K, 0,0)$ kondisi ini menunjukan kepunahan yang terjadi pada populasi prey terinfeksi dan predator.

3. $E_{2}:=\left(\frac{\delta}{b_{1}}, 0, \frac{r\left(b_{1} K-\delta\right)}{K m_{1} b_{1}}\right)$ kondisi yang menunjukan ketika populasi prey terinfeksi punah.

4. $E_{3}:=\left(\frac{\alpha}{\beta}, \frac{r(\beta K-\alpha)}{\beta(\beta K+r)}, 0\right)$ titik ini menunjukan kepunahan pada populasi predator.

5. $E_{4}:=\left(X, \frac{\delta-b_{1} X}{b_{2}}, \frac{\beta X-\alpha}{m_{2}}\right)$ dimana $X=\frac{m_{2} \delta(\beta K+r)-b_{2} K\left(r m_{2}+m_{1} \alpha\right)}{b_{1} m_{2}(\beta K+r)-b_{2}\left(r m_{2}+m_{1} \beta K\right)}$ kondisi yang menunjukan eksistensi seluruh populasi.

Berdasarkan kondisi biologis maka $E_{i}, i=0 . .4$ merupakan titik kesetimbangan biologis dari model (1) jika $E_{i} \in \mathbb{R}_{+}^{3}$ dengan $\mathbb{R}_{+}^{3}:=\left\{\left(x_{S}, x_{I}, y\right) \mid x_{S} \geq 0, x_{I} \geq 0, y \geq 0,\left(x_{S}, x_{I}, y\right) \in \mathbb{R}\right\}$. Dengan demikian diperoleh teorema sebagai berikut.

Teorema 2. (i) $E_{0}$ dan $E_{1}$ adalah titik kesetimbangan biologis.

(ii) $E_{2}$ adalah titik kesetimbangan biologis jika $K>\frac{\delta}{b_{1}}$.

(iii) $E_{3}$ adalah titik kesetimbangan biologis jika $K>\frac{\alpha}{\beta}$.

(iv) $E_{4}$ adalah titik kesetimbangan biologis jika $\frac{\alpha}{\beta}<X<\frac{\delta}{b_{1}}$ dan; $m_{2}>\max \left\{m_{2}{ }^{*}, \hat{m}_{2}\right\}$ atau $m_{2}<\min \left\{m_{2}{ }^{*}, \hat{m}_{2}\right\}$ dengan $m_{2}^{*}=\frac{b_{2} K\left(r m_{2}+m_{1} \alpha\right)}{\delta(\beta K+r)}$ dan $\hat{m}_{2}=\frac{b_{2}\left(r m_{2}+m_{1} \beta K\right)}{b_{1}(\beta K+r)}$.

bukti. (i) Karena $E_{0}$ dan $E_{1}$ selalu berada di $\mathbb{R}_{+}^{3}$, maka $E_{0}$ dan $E_{1}$ adalah titik kesetimbangan biologis.

(ii) Jika $K>\frac{\delta}{b_{1}}$ maka $\frac{r\left(b_{1} K-\delta\right)}{K m_{1} b_{1}}>0$ sehingga $E_{2} \in \mathbb{R}_{+}^{3}$. Dengan demikian $E_{2}$ merupakan titik kesetimbangan biologis.

(iii) Jika $K>\frac{\alpha}{\beta}$ maka $\frac{r(\beta K-\alpha)}{\beta(\beta K+r)}>0$ sehingga $E_{2} \in \mathbb{R}_{+}^{3}$. Akibatnya $E_{3}$ merupakan titik kesetimbangan biologis.

(iv) Akan ditunjukkan bahwa $\frac{\delta-b_{1} X}{b_{2}}>0, \frac{\beta X-\alpha}{m_{2}}>0$, dan $X>0$ sehingga $E_{4} \in \mathbb{R}_{+}^{3}$. Perhatikan bahwa $\frac{\delta-b_{1} X}{b_{2}}>0$ jika $X<\frac{\delta}{b_{1}}$, dan $\frac{\beta X-\alpha}{m_{2}}>0$ jika $X>\frac{\alpha}{\beta}$. Oleh karena itu, jika $\frac{\alpha}{\beta}<X<\frac{\delta}{b_{1}}$ maka $\frac{\delta-b_{1} X}{b_{2}}>0$ dan $\frac{\beta X-\alpha}{m_{2}}>0$ secara simultan. Selanjutnya akan diidentifikasi kondisi parameter sehingga $X>0$. Perhatikan bahwa $X>0$ jika

(a) $m_{2} \delta(\beta K+r)-b_{2} K\left(r m_{2}+m_{1} \alpha\right)>0$ dan $b_{1} m_{2}(\beta K+r)-b_{2}\left(r m_{2}+m_{1} \beta K\right)>0$, atau;

(b) $m_{2} \delta(\beta K+r)-b_{2} K\left(r m_{2}+m_{1} \alpha\right)<0$ dan $b_{1} m_{2}(\beta K+r)-b_{2}\left(r m_{2}+m_{1} \beta K\right)<0$.

Jika $m_{2}>\max \left\{m_{2}{ }^{*}, \hat{m}_{2}\right\}$ maka poin (a) terpenuhi sehingga $X>0$ yang mengakibatkan $E_{4} \in \mathbb{R}_{+}^{3}$. Jika $m_{2}<\min \left\{m_{2}{ }^{*}, \hat{m}_{2}\right\}$ maka poin (b) terpenuhi sehingga $X>0$ yang mengakibatkan $E_{4} \in \mathbb{R}_{+}^{3}$. Akibatnya $E_{4}$ adalah titik kesetimbangan biologis.

Selanjutnya akan dipelajari dinamika dari model (1) secara lokal disekitar titik-titik kesetimbangan $E_{i}, i=0 . .4$. Dinamika secara lokal dari model (1) tersebut dipelajari dengan terlebih dahulu melakukan pelinearan disekitar titik-titik kesetimbangan. Hasil pelinearan memberikan matriks Jacobi sebagai berikut.

$$
J\left(x_{s}, x_{i}, y\right)=\left[\begin{array}{ccc}
r\left(1-\frac{2 x_{s}+x_{i}}{K}\right)-m_{1} y-\beta x_{i} & -\frac{r x_{s}}{K}(\beta K+r) & -m_{1} x_{s} \\
\beta x_{i} & \beta x_{s}-m_{2} y-\alpha & m_{2} x_{i} \\
y b_{1} & y b_{2} & b_{1} x_{s}+b_{2} x_{i}-\delta
\end{array}\right]
$$

Kestabilan dari titik-titik kesetimbangan secara lokal diberikan oleh beberapa teorema berikut.

Teorema 3. E $E_{0}$ adalah titik kesetimbangan tidak stabil tipe pelana.

bukti. Dengan mensubtitusikan $E_{0}$ ke matriks Jacobi (5) diperoleh 


$$
\left.J\left(x_{s}, x_{i}, y\right)\right|_{E_{0}}=\left[\begin{array}{ccc}
r & 0 & 0 \\
0 & -\alpha & 0 \\
0 & 0 & -\delta
\end{array}\right] .
$$

Dari matriks Jacobi (6) diperoleh nilai eigen

$$
\lambda_{1}=r, \lambda_{2}=-\alpha, \text { dan } \lambda_{3}=-\delta .
$$

Karena ada satu nilai eigen bernilai positif dan dua lainnya bernilai negatif maka $E_{0}$ tidak stabil tipe pelana.

Teorema 4. E $E_{1}$ stabil asimtotik lokal jika $K<\min \left\{\frac{\alpha}{\beta}, \frac{\delta}{b_{1}}\right\}$.

bukti. Di titik kesetimbangan $E_{1}$, matriks Jacobi (5) menjadi

$$
\left.J\left(x_{s}, x_{i}, y\right)\right|_{E_{1}}=\left[\begin{array}{ccc}
-r & -(\beta K+r) & -m_{1} K \\
0 & \beta K-\alpha & 0 \\
0 & 0 & b_{1} K-\delta
\end{array}\right],
$$

yang memberikan nilai eigen: $\lambda_{1}=-r, \lambda_{2}=\beta K-\alpha$, dan $\lambda_{2}=b_{1} K-\delta$. Jelas bahwa $\lambda_{1}<0$. Selanjutnya jika $K<\min \left\{\frac{\alpha}{\beta}, \frac{\delta}{b_{1}}\right\}$ mengakibatkan $K<\frac{\alpha}{\beta}$ dan $K<\frac{\delta}{b_{1}}$ sehingga berturut-turut memberikan $\lambda_{2}<0$ dan $\lambda_{3}<0$. Dengan demikian $E_{1}$ stabil asimtotik lokal.

Berdasarkan Teorema 4 dan syarat eksistensi pada Teorema 2 terlihat bahwa syarat kestabilan $E_{1}$ bertentangan dengan syarat eksistensi $E_{2}$ dan $E_{3}$. Dengan demikian diperoleh Lema 5.

Lema 5. Jika $E_{1}$ stabil asimtotik lokal maka $E_{2}$ dan $E_{3}$ bukan merupakan titik kesetimbangan biologis.

Selanjutnya akan dipelajari kestabilan dari titik kesetimbangan $E_{2}$. Perhatikan teorema berikut.

Teorema 6. E $E_{2}$ stabil asimtotik lokal jika $\beta<\frac{\alpha b_{1}}{\delta}+\frac{\left(b_{1} K-\delta\right) r m_{2}}{\delta m_{1} K}$.

bukti. Matriks Jacobi model (1) di titik kesetimbangan $E_{2}$ yaitu

$$
\left.J\left(x_{s}, x_{i}, y\right)\right|_{E_{2}}=\left[\begin{array}{ccc}
-\frac{r \delta}{b_{1} K} & -\frac{r \delta b_{1}+\beta \delta b_{1} K}{b_{1}^{2} K} & -\frac{m_{1} \delta}{b_{1}} \\
0 & \frac{K m_{1} \beta \delta-r\left(b_{1} K-\delta\right) m_{2}-K m_{1} b_{1} \alpha}{k m_{1} b_{1}} & 0 \\
\frac{r\left(b_{1} K-\delta\right)}{K m_{1}} & \frac{r b_{2}\left(b_{1} K-\delta\right)}{K m_{1} b_{1}} & 0
\end{array}\right] .
$$

Matriks Jacobi (8) memberikan nilai eigen

$$
\begin{aligned}
\lambda_{1} & =-\frac{\alpha K m_{1} b_{1}+\left(b_{1} K-\delta\right) r m_{2}-\delta \beta K m_{1}}{K m_{1} b_{1}}, \\
\lambda_{2,3} & =\frac{-\delta r \pm \sqrt{\delta r \hat{\Delta}}}{2 b_{1} K}
\end{aligned}
$$

dengan $\hat{\Delta}=\delta r-4 b_{1} K\left(b_{1} K-\delta\right)$. Perhatikan bahwa $\lambda_{1}<0$ jika $\beta<\frac{\alpha b_{1}}{\delta}+\frac{\left(b_{1} K-\delta\right) r m_{2}}{\delta m_{1} K}$. Dengan demikian, kestabilan $E_{2}$ bergantung pada $\lambda_{2}$ dan $\lambda_{3}$. Untuk $\hat{\Delta}<0$ maka $\lambda_{2,3} \in \mathbb{C}$ dengan $\operatorname{Re}\left(\lambda_{i}\right)<0, i=2,3$ sehingga $E_{2}$ stabil asimtotik lokal. Selanjutnya untuk $\hat{\Delta} \geq 0$ mengakibatkan $\lambda_{i} \in \mathbb{R}, i=2,3$. Dengan mudah dapat ditunjukkan bahwa $\lambda_{i}<0, i=2,3$ yang juga mengakibatkan $E_{2}$ stabil asimtotik lokal.

Teorema 7. E $E_{3}$ stabil asimtotik lokal jika $b_{2}<\frac{\left(\beta \delta-\alpha b_{1}\right)(K \beta+r)}{(\beta K-\alpha) r}$. 
bukti. Dengan mensubtitusikan $E_{3}$ ke matriks Jacobi (5) diperoleh

$$
\left.J\left(x_{s}, x_{i}, y\right)\right|_{E_{3}}=\left[\begin{array}{cccc}
r-\frac{2 r \alpha}{\beta K}-\frac{r(\beta K-\alpha)}{\beta K(\beta K+r)}-\frac{r(\beta K-\alpha)}{\beta K+r} & -\frac{\alpha(\beta K+r)}{\beta K} & -\frac{m_{1} \alpha}{\beta} \\
\frac{r(\beta K-\alpha)}{\beta K+r} & 0 & -\frac{m_{2} r(\beta K-\alpha)}{\beta(\beta K+r)} \\
0 & 0 & \frac{b_{1} \alpha}{\beta}+\frac{b_{2} r(\beta K-\alpha)}{\beta(\beta K+r)}-\delta
\end{array}\right]
$$

yang memberikan nilai eigen

$$
\begin{array}{ll}
\lambda_{1}=-\frac{\left(\beta \delta-\alpha b_{1}\right)(K \beta+r)-(\beta K-\alpha) r b_{2}}{\beta(\beta K+r)}, & \lambda_{3}=\frac{-\alpha r-\sqrt{\alpha r \tilde{\Delta}}}{2 \beta K}, \\
\lambda_{2}=\frac{-\alpha r+\sqrt{\alpha r \tilde{\Delta}}}{2 \beta K}, & \tilde{\Delta}=\alpha r-4 \beta K(\beta K-\alpha)
\end{array}
$$

Jika $b_{2}<\frac{\left(\beta \delta-\alpha b_{1}\right)(K \beta+r)}{(\beta K-\alpha) r}$ maka $\lambda_{1}<0$. Selanjutnya, untuk $\tilde{\Delta}<0$ maka $\lambda_{i} \in \mathbb{C}, i=2,3 \operatorname{dengan} \operatorname{Re}\left(\lambda_{2,3}\right)<0$ sehingga $E_{3}$ stabil asimtotik lokal. Jika $\tilde{\Delta}>0$ maka dengan mudah dapat dibuktikan bahwa $\lambda_{2,3}<0$. Dengan demikian $E_{3}$ stabil asimtotik lokal.

Teorema 8. Misalkan:

$$
\begin{aligned}
& \xi_{1}=\frac{r X}{K}, \xi_{2}=\frac{m_{1} X b_{1}(\beta X-\alpha)}{m_{2}}+\frac{\beta X(\beta K+r)\left(\delta-b_{1} X\right)}{b_{2} K}+(\beta X-\alpha)\left(\delta-b_{1} X\right), \\
& \xi_{3}=\frac{m_{1} \beta X\left(\delta-b_{2} X\right)(\beta X-\alpha)}{m_{2}}+\frac{r X(\beta X-\alpha)\left(\delta-b_{1} X\right)}{K}-\frac{X b_{1}(\beta K+r)\left(\delta-b_{1} X\right)(\beta X-\alpha)}{b_{2} K} .
\end{aligned}
$$

$E_{4}$ stabil asimtotik lokal jika $\xi_{3}>0$ dan $\xi_{1} \xi_{2}>\xi_{3}$.

bukti. Dengan mengevaluasi matriks Jacobi (5) pada titik $E_{4}$, diperoleh

$$
\left.J\left(x_{s}, x_{i}, y\right)\right|_{E_{4}}=\left[\begin{array}{ccc}
-\frac{r X}{K} & -\frac{X}{K}(\beta K+r) & -m_{1} X \\
\frac{\beta\left(\delta-b_{1} X\right)}{b_{2}} & 0 & -\frac{m_{2}\left(\delta-b_{1} X\right)}{b_{2}} \\
\frac{b_{1}(\beta X-\alpha)}{m_{2}} & \frac{b_{2}(\beta X-\alpha)}{m_{2}} & 0
\end{array}\right]
$$

yang memberikan persamaan karakteristik $P(\lambda)=\lambda^{3}+\xi_{1} \lambda^{2}+\xi_{2} \lambda+\xi_{3}=0$. Dengan menggunakan kriteria Routh-Hurwitz [24], $E_{4}$ stabil asimtotik lokal jika $\xi_{3}>0$ dan $\xi_{1} \xi_{2}>\xi_{3}$.

\section{Simulasi Numerik}

Pada tahapan ini, diberikan simulasi numerik menggunakan metode Runge-Kutta orde-4 yang diaplikasikan pada Phyton 3.7 [25]. Karena model yang dipelajari tidak merujuk pada suatu kasus khusus yang terjadi pada interaksi dua spesies dalam suatu habitat, maka pemilihan parameter disesuaikan dengan kondisi kestabilan yang diperoleh pada hasil analisis sebelumnya. Nilai-nilai parameter tersebut diberikan pada Tabel 1.

Tabel 1. Nilai awal dan parameter yang digunakan dalam simulasi numerik

\begin{tabular}{ccccccccccc}
\hline \multirow{2}{*}{ Simulasi } & Titik & \multicolumn{10}{c}{ Parameter } \\
\cline { 3 - 11 } & Kesetimbangan & $K$ & $\alpha$ & $\beta$ & $r$ & $b_{1}$ & $b_{2}$ & $m_{1}$ & $m_{2}$ & $\delta$ \\
\hline Simulasi 1 & $E_{0}$ & 9 & 0.9 & 0.1 & 1 & 0.1 & 0.45 & 0.8 & 0.9 & 0.9 \\
Simulasi 2 & $E_{1}$ & 10 & 2.3 & 0.2 & 5 & 0.3 & 0.25 & 0.8 & 0.9 & 3.5 \\
Simulasi 3 & $E_{2}$ & 6 & 2 & 3.2 & 1 & 2.65 & 1 & 3 & 3.5 & 2.353 \\
Simulasi 4 & $E_{3}$ & 8 & 1 & 3 & 5 & 1 & 2 & 3 & 4 & 3 \\
Simulasi 5 & $E_{4}$ & 10 & 0.1 & 0.5 & 1 & 0.4 & 0.4 & 0.74 & 0.45 & 0.7 \\
\hline
\end{tabular}

Berdasarkan Tabel 1 diperoleh dinamika dari model (1) sebagai berikut: 


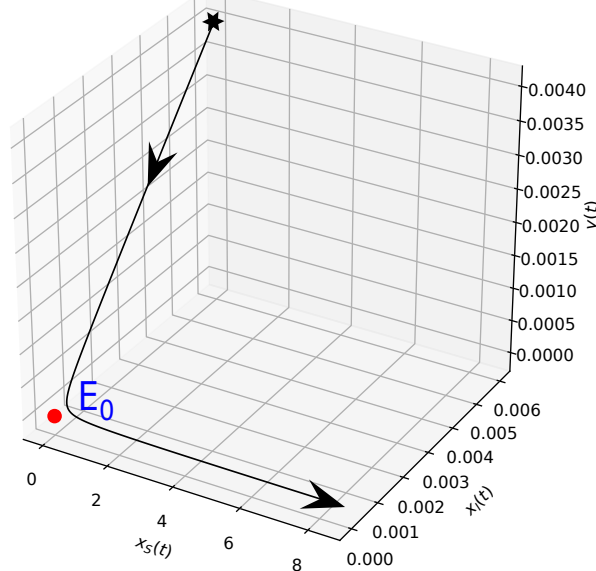

(a) Dinamika di sekitar $E_{0}$

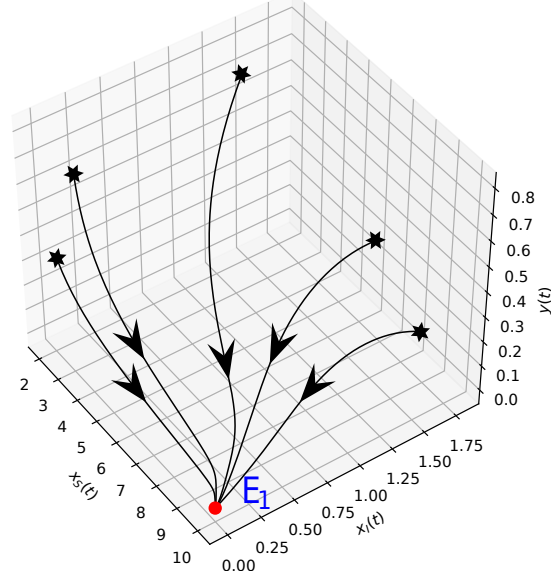

(b) Dinamika di sekitar $E_{1}$

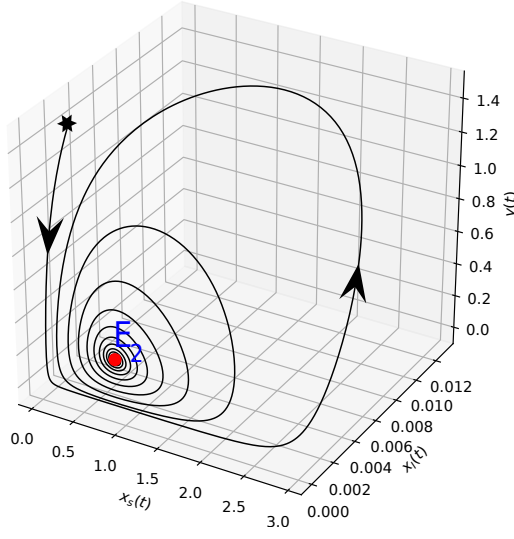

(c) Dinamika di sekitar $E_{2}$

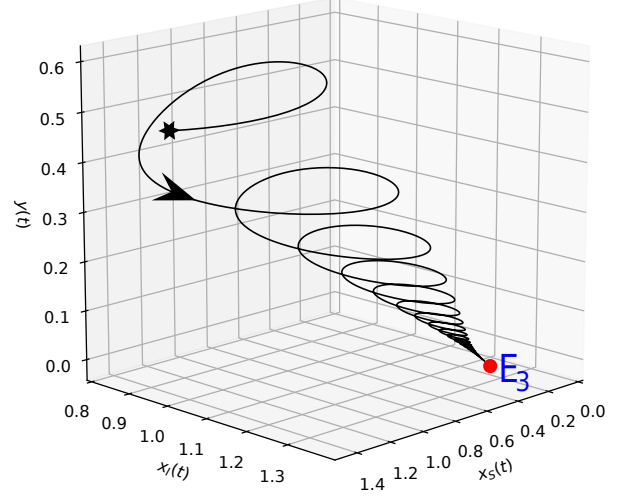

(d) Dinamika di sekitar $E_{3}$

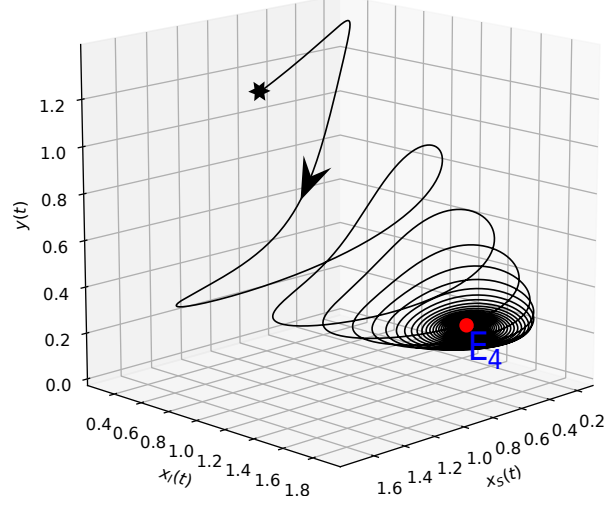

(e) Dinamika disekitar $E_{4}$

Gambar 1. Potret fase di sekitar titik kesetimbangan $E_{0}, E_{1}, E_{2}, E_{3}$, dan $E_{4}$ dengan nilai-nilai parameter seperti pada Tabel 1.

(i) Berdasarkan Teorema 3, titik kesetimbangan $E_{0}$ tidak stabil tipe pelana. Oleh karena itu dipilih nilai-nilai parameter seperti pada Tabel 1: Simulasi 1, sehingga diperoleh potret fase seperti pada Gambar 1a. Awalnya solusi numerik menuju ke titik $E_{0}$, tapi disaat solusinya sudah mendekati titik $E_{0}$ lalu menjauhi titik tersebut. Dengan nilai awal yang diberikan, solusi di awal waktu mengindikasikan populasi yang menuju kepunahan, tapi ketika semua populasinya akan punah terjadi peningkatan jumlah populasi pada prey rentan.

(ii) Selanjutnya diberikan nilai-nilai parameter sesuai dengan Tabel 1: Simulasi 2. Berdasarkan Teorema 4, titik kesetimbangan $E_{1}$ stabil asimtotik lokal. Semua solusi dengan nilai-nilai awal yang cukup dekat dengan $E_{1}$ 
akan menuju $E_{1}$ yang mengindikasikan kepunahan prey dengan penyakit dan kepunahan predator sehingga dalam ekosistem tersebut hanya ada prey rentan. Lihat Gambar $1 b$.

(iii) Untuk menunjukkan dinamika di sekitar $E_{2}$, dipilih nilai-nilai parameter seperti pada Tabel 1: Simulasi 3. Solusi yang cukup dekat dengan $E_{2}$ bergerak mendekati $E_{2}$ secara periodik seperti pada Gambar $1 c$. Hal ini sesuai dengan Teorema 6 yang menyatakan kejadian punahnya populasi prey dengan penyakit sehingga yang tersisa adalah prey rentan dan predator.

(iv) Pada Tabel 1: Simulasi 4, dipilih nilai-nilai parameter yang bersesuaian dengan Teorema 7. Dengan nilai awal yang cukup dekat dengan $E_{3}$ diperoleh solusi yang berosilasi menuju titik kesetimbangan $E_{3}$. Dapat dilihat pada Gambar 1d bahwa predator akan punah sehingga pada ekosistem tersebut yang mampu bertahan hanya prey saja, meskipun tetap ada penyakit yang menyebar di dalam populasi prey.

(v) Diakhir simulasi, diberikan nilai-nilai parameter seperti pada Tabel 1: Simulasi 5. Berdasarkan Teorema 8, terdapat titik kesetimbangan $E_{4}$ yang stabil asimtotik lokal yang mengindikasikan eksistensi dari semua populasi seperti pada Gambar 1e. Solusi bergerak secara periodik ke titik $E_{4}$.

Dengan demikian, telah diberikan simulasi numerik yang mendukung hasil analisis yang diberikan pada Pokok Bahasan 3.

\section{Kesimpulan}

Model predator-prey tipe Gause dengan wabah penyakit pada prey telah dipelajari. Hasil analisis menunjukkan bahwa model yang dibangun layak secara biologis karena memiliki solusi yang positif dan terbatas. Model yang dibangun memiliki lima titik kesetimbangan dengan syarat-syarat eksistensi tertentu. Selain itu juga diberikan syarat-syarat yang harus dipenuhi secara biologis agar setiap titik-titik kesetimbangan stabil asimtotik lokal. Untuk mendukung hasil analisis yang dilakukan, diberikan simulasi numerik dengan nilai-nilai parameter merujuk pada kondisi eksistensi dan kestabilan dari setiap titik kesetimbangan yang diperoleh sebelumnya. Secara umum, teridentifikasi dari model yang ada bahwa tidak mungkin terjadi kepunahan dari seluruh populasi. Lebih khusus lagi, untuk populasi prey terinfeksi dan predator dapat punah, namun untuk populasi prey rentan tidak mungkin punah. Hal ini dikarenakan daya dukung populasi prey rentan bergantung kepada lingkungannya sedangkan daya dukung predator bergantung pada kepadatan populasi prey.

\section{Referensi}

[1] H. S. Panigoro, "Analisis dinamik sistem predator-prey model Leslie-Gower dengan pemanenan secara konstan terhadap predator," Euler, vol. 2, no. 1, hal. 1-12, 2014.

[2] H. S. Panigoro dan D. Savitri, "Bifurkasi Hopf pada model Lotka-Volterra orde-fraksional dengan efek Allee aditif pada predator," Jambura Journal of Biomathematics, vol. 1, no. 1, hal. 16-24, 2020.

[3] L. K. Beay dan M. Saija, "A stage-structure Rosenzweig-MacArthur model with effect of prey refuge," Jambura Journal of Biomathematics, vol. 1, no. 1, hal. 1-7, 2020.

[4] D. Savitri dan H. S. Panigoro, "Bifurkasi Hopf pada model prey-predator-super predator dengan fungsi respon yang berbeda," Jambura Journal of Biomathematics, vol. 1, no. 2, hal. 65-70, 2020.

[5] H. S. Panigoro, A. Suryanto, W. M. Kusumawinahyu, dan I. Darti, “Continuous threshold harvesting in a Gause-type predator-prey model with fractional-order," in AIP Conference Proceedings, vol. 2264, no. 1. AIP Publishing, 2020, hal. 040001.

[6] — - "A Rosenzweig-MacArthur model with continuous threshold harvesting in predator involving fractional derivatives with power law and mittag-leffler kernel," Axioms, vol. 9, no. 4, hal. 122, 2020.

[7] Y. Yao, "Bifurcations of a Leslie-Gower prey-predator system with ratio-dependent Holling IV functional response and prey harvesting," Mathematical Methods in the Applied Sciences, vol. 43, no. 5, hal. 2137-2170, 2020.

[8] P. Mishra, S. Raw, dan B. Tiwari, “On a cannibalistic predator-prey model with prey defense and diffusion," Applied Mathematical Modelling, vol. 90, hal. 165-190, 2021.

[9] K. Sun, T. Zhang, dan Y. Tian, "Dynamics analysis and control optimization of a pest management predator-prey model with an integrated control strategy," Applied Mathematics and Computation, vol. 292, hal. 253-271, 2017.

[10] A. Suryanto dan I. Darti, "Dynamics of Leslie-Gower pest-predator model with disease in pest including pest-harvesting and optimal implementation of pesticide," International Journal of Mathematics and Mathematical Sciences, vol. 2019, no. June, hal. 1-9, 2019.

[11] T. Yu, Y. Tian, H. Guo, dan X. Song, “Dynamical analysis of an integrated pest management predator-prey model with weak Allee effect," Journal of Biological Dynamics, vol. 13, no. 1, hal. 218-244, 2019.

[12] H. S. Panigoro dan E. Rahmi, “Modifikasi sistem predator-prey: dinamika model Leslie-Gower dengan daya dukung yang tumbuh logistik," SEMIRATA MIPAnet, hal. 94-103, 2017.

[13] T. Kar, A. Ghorai, dan S. Jana, "Dynamics of pest and its predator model with disease in the pest and optimal use of pesticide," Journal of Theoretical Biology, vol. 310, hal. 187-198, 2012. 
[14] H. S. Panigoro, A. Suryanto, W. M. Kusumawinahyu, dan I. Darti, “Dynamics of an eco-epidemic predator-prey model involving fractional derivatives with power-law and Mittag-Leffler kernel," Symmetry, vol. 13, no. 5, hal. 785, 2021.

[15] A. A. Berryman, "The origins and evolution of predator-prey theory," Ecology, vol. 73, no. 5, hal. 1530-1535, 1992.

[16] H. S. Panigoro, A. Suryanto, W. M. Kusumahwinahyu, dan I. Darti, "Dynamics of a fractional-order predator-prey model with infectious diseases in prey," Communication in Biomathematical Sciences, vol. 2, no. 2, hal. 105, 2019.

[17] N. Hasan, R. Resmawan, dan E. Rahmi, "Analisis kestabilan model eko-epidemiologi dengan pemanenan konstan pada predator," Jurnal Matematika, Statistika dan Komputasi, vol. 16, no. 2, hal. 121, 2019.

[18] S. Maisaroh, R. Resmawan, dan E. Rahmi, "Analisis kestabilan model predator-prey dengan infeksi penyakit pada prey dan pemanenan proporsional pada predator," Jambura Journal of Biomathematics, vol. 1, no. 1, hal. 8-15, 2020.

[19] Y. H. Hsieh dan C. K. Hsiao, "Predator-prey model with disease infection in both populations," Mathematical Medicine and Biology, vol. 25, no. 3, hal. 247-266, 2008.

[20] F. Rihan dan C. Rajivganthi, "Dynamics of fractional-order delay differential model of prey-predator system with Holling-type III and infection among predators," Chaos, Solitons Fractals, vol. 141, hal. 110365, 2020.

[21] M. S. Rahman dan S. Chakravarty, "A predator-prey model with disease in prey," Nonlinear Analysis: Modelling and Control, vol. 18, no. 2, hal. 191-209, 2013.

[22] A. S. Purnomo, I. Darti, dan A. Suryanto, "Dynamics of eco-epidemiological model with harvesting," AIP Conference Proceedings, vol. 1913, no. December 2017, 2017.

[23] C. Roberts, Ordinary Differential Equations. Chapman and Hall/CRC, 2010.

[24] M. Z. Ndii, Pemodelan matematika. Yogyakarta: Penerbit Deepublish, 2018.

[25] S. Lynch, Dynamical Systems with Applications using Python. Manchester: Springer Nature, 2018.

2021 by the Author(s). This article is an open access article distributed under the terms and conditions of the Creative Commons Attribution-NonComercial 4.0 International License. Editorial of JJBM: Department of Mathematics, State University of Gorontalo, Jln. Prof. Dr. Ing. B. J. Habibie, Bone Bolango 96119, Indonesia. 


\section{Submit your manuscript at http://ejurnal.ung.ac.id/}

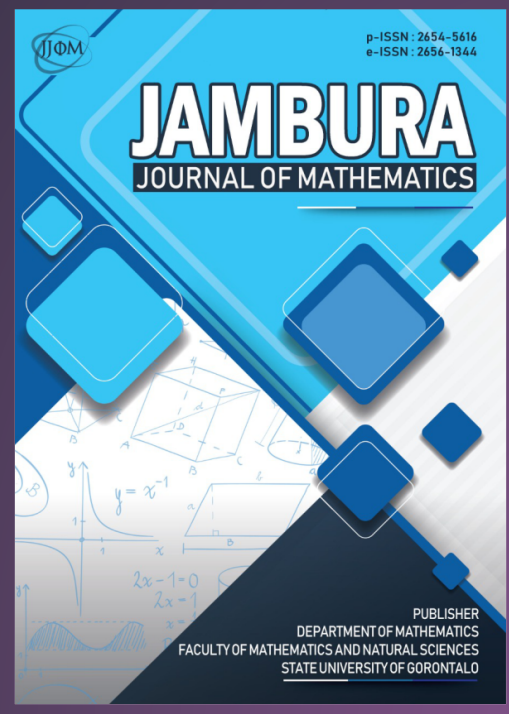

Jambura Journal of Mathematics

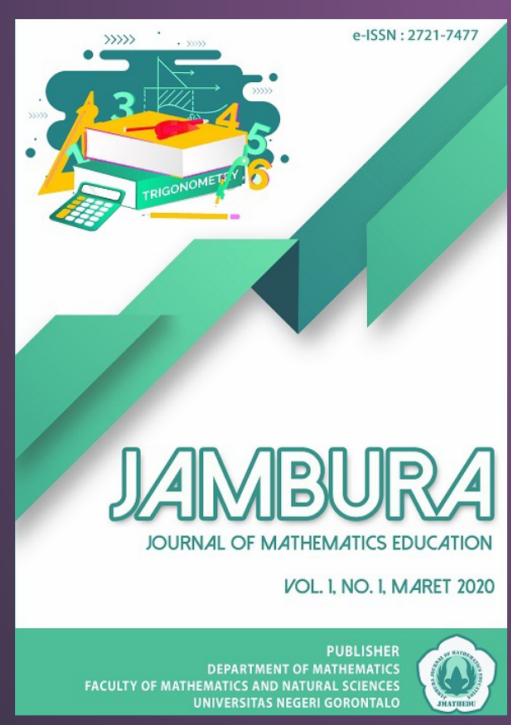

Jambura Journal of Mathematics Education
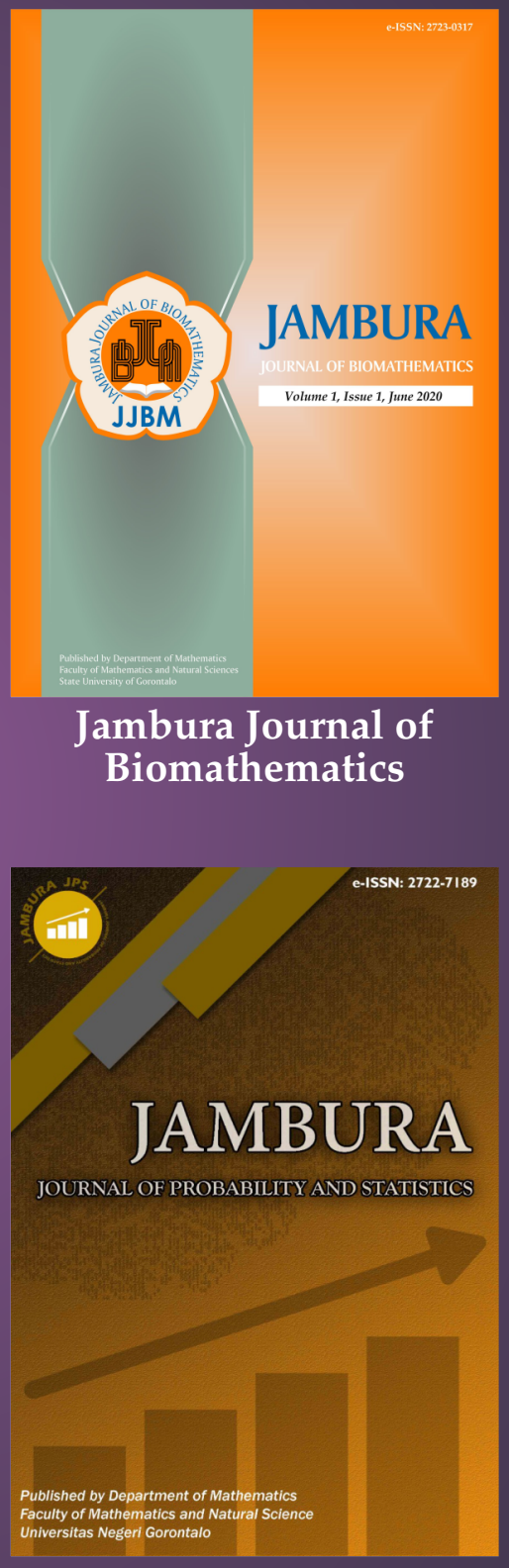

Jambura Journal of Probability and Statistics

Published by

Department of Mathematics

Faculty of Mathematics and Natural Sciences

State University of Gorontalo 